\title{
Maternal and perinatal outcomes of hypertensive disorders of pregnancy in Ethiopia: systematic review and meta- analysis
}

Amanual Getnet Mersha ${ }^{1 *}$, Tadesse Melaku Abegaz ${ }^{2}$ and Mohammed Assen Seid ${ }^{2}$

\begin{abstract}
Background: Hypertensive disorders of pregnancy complicate around 6\% of pregnancies and accounts for 19\% of maternal death in Ethiopia. The current review aimed to assess maternal and perinatal outcomes of pregnancies complicated by hypertension in Ethiopia.

Methods: A systematic review and meta-analysis was done on the outcome of hypertensive disorder among pregnant women in Ethiopia. Literature search was made in five databases and Statistical analyses were carried out by using Stata 14 software. The pooled prevalence of maternal death, HELLP syndrome, perinatal death, and low birth weight was calculated using a random-effects model. Egger's test and funnel plot were used to evaluate publication bias. The Cochran $\mathrm{Q}$ test and $\mathrm{I}^{2}$ test statistics were used to test the heterogeneity of studies.

Result: Thirteen studies included in the review, with an overall sample size of 5894 women diagnosed to have hypertensive disorder of pregnancy. The pooled prevalence of maternal death was estimated to be $4 \%$ (95\% Cl: 2 , $6 \%)$. The pooled prevalence of HELLP syndrome was 13\% (95\% Cl: 10, 16\%). Other complications such as pulmonary edema, kidney injury, hepatic injury, placental abruption, and aspiration pneumonia were also reported. Perinatal death was observed in one-fourth of women with HDP 25\% (95\% Cl: 18, 32\%). The pooled prevalence of low birth weight neonate in a woman with HDP is $37 \%(95 \% \mathrm{Cl}, 27,48 \%)$.

Conclusions: In Ethiopia, the prevalence of perinatal and maternal mortality among pregnant women with one of the hypertensive disorders were found to be higher than rates reported from high income as well as most of the low and middle income countries. For instance, one in four of pregnancies complicated by hypertensive disorder end up in perinatal death in Ethiopia. HELLP syndrome, placental abruption, pulmonary edema, renal damage, prematurity, perinatal asphyxia, and low birth weight were also commonly reported. To improve the health outcomes of hypertensive disorders of pregnancy, it is recommended to improve utilization of maternal health service; early detection and early referral of pregnant women with hypertensive disorder; advocating policies and strategies that improves the quality of health care that a pregnant woman and her newborn receive.
\end{abstract}

Keywords: Ethiopia, Hypertensive disorders of pregnancy, Meta-analysis, Outcomes, Systematic review

\footnotetext{
* Correspondence: amanuelget16@gmail.com

${ }^{1}$ Department of Gynecology and Obstetrics, School of Medicine, College of

Medicine and Health Sciences, University of Gondar, P.O. Box: 196, Gondar,

Ethiopia

Full list of author information is available at the end of the article
}

(c) The Author(s). 2019 Open Access This article is distributed under the terms of the Creative Commons Attribution 4.0 International License (http://creativecommons.org/licenses/by/4.0/), which permits unrestricted use, distribution, and reproduction in any medium, provided you give appropriate credit to the original author(s) and the source, provide a link to the Creative Commons license, and indicate if changes were made. The Creative Commons Public Domain Dedication waiver (http://creativecommons.org/publicdomain/zero/1.0/) applies to the data made available in this article, unless otherwise stated. 


\section{Background}

Globally, hypertensive disorders of pregnancy complicate $3-10 \%$ of all pregnancies and it is a major cause of maternal and perinatal complications [1]. A recent review reported that hypertensive disorders of pregnancy complicate around 6\% of all pregnancies in Ethiopia [2]. Hypertensive disorders of pregnancy (HDP) accounts for $18 \%$ of maternal deaths worldwide, with an estimated number of about 62, 000-77, 000 deaths occur each year [3]. Due to the existing low level of health service utilization and poor quality of maternal and neonatal care, the maternal and perinatal morbidities are much higher in low and middle -income countries (LMICs) [4, 5]. For instance, $19 \%$ of all maternal deaths in Ethiopia are attributed to hypertensive disorders of pregnancy [6]. Hypertensive disorders of pregnancy were also reported to account for $30 \%$ of maternal mortality in Ghana [5].

Maternal complications of hypertensive disorders of pregnancy include placental abruption, pulmonary edema, thrombocytopenia, hemolytic anemia, stroke, recurrent seizure, renal damage, hepatic injury and others [7]. HELLP syndrome comprises of the following: haemolysis, elevated liver enzymes, and low platelets. HELLP syndrome occurs in about 0.5 to $0.9 \%$ of all pregnancies and complicates 10 to $20 \%$ of women with severe preeclampsia. HELLP syndrome is one of the common cause of maternal and fetal mortality among pregnant women with hypertension [8].

According to the 2016 Demographic and Health Survey (EDHS), the perinatal mortality rate in Ethiopia was 33 per 1000 pregnancies by the end of 2016 [9]. Perinatal mortality is three to five folds higher in women with preeclampsia/eclampsia syndrome as compared to those without the disorders [10, 11]. Different studies documented high perinatal mortality rate among women with hypertensive disorders of pregnancy. For instance, the rate of perinatal death was found to be $317 / 1000$ births in Ethiopia [29]; 230/1000 births in Pakistan [12]; and, 144/ 1000 births in Turkey [13]. A Southern Ethiopia study reported a considerable association of perinatal death with maternal death, antepartum occurrence of the disease, low birth weight, hepatic injury, earlier gestational age at diagnosis, having eclampsia, and multipara [22].

Although hypertensive disorders of pregnancy are among the leading causes of maternal and perinatal deaths in Ethiopia, there is no pooled national evidence that demonstrates the feto-maternal outcomes of pregnancies complicated by the disorder. Therefore, the current review aimed to assess the maternal as well as perinatal outcomes of pregnancies complicated by hypertension in Ethiopia.

\section{Methods and materials}

\section{Study design and search strategy}

A systemic review and meta-analysis was conducted to assess maternal and fetal outcomes of hypertensive disorders of pregnancy in Ethiopia. The studies were retrieved through internet search from the databases of MEDLINE, Scopus, PubMed, ScienceDirect, and Google Scholar. A combination of keywords and phrases like: preeclampsia (Mesh), preeclamp*(all fields), eclampsia (Mesh),eclamp*(all fields), hypertensive disorders of pregnancy (Mesh), hypertensive disorders of pregnancy (all fields), fetal outcome (Mesh), fetal outcome (all fields), maternal outcome (Mesh), maternal outcome (all fields), gestational hypertension (Mesh),gestational hypertension (all fields), pregnancy induced hypertension (all fields), and Ethiopia (all fields), were used to search articles in the databases. The reference lists of identified studies were also screened to recover other articles and one unpublished study was retrieved from Addis Ababa University electronic library. All published articles up to 21 September 2018 were included in the review.

\section{Eligibility criteria}

All observational studies that reported at least one of the maternal and/or fetal outcomes of hypertensive disorders of pregnancy and conducted in Ethiopia were included in the current review.

\section{Operational definitions of outcomes}

The primary outcomes of interest included in the Metaanalysis are maternal death, HELLP syndrome, perinatal death, and low birth weight. The secondary outcomes included in the review are preterm delivery, perinatal asphyxia, acute kidney injury, aspiration pneumonia, pulmonary edema, ANC service utilization, and placental abruption.

\section{Maternal death}

The death of a woman while pregnant or within fortytwo completed days of termination of pregnancy irrespective of duration and site of pregnancy, from any cause related to or aggravated by the pregnancy or by its management but not due to accidental or incidental causes.

\section{HELLP syndrome}

A syndrome consists of haemolysis $(\mathrm{H})$, elevated liver enzymes (EL), and Low platelet count (LP).

\section{Perinatal death}

The death of a fetus/neonate in the perinatal period (from age of viability or twenty-eight weeks of gestation in Ethiopian context to first six days after birth). 


\section{Preterm delivery}

Birth of baby after age of viability or twenty-eight weeks of gestation in Ethiopian context but before thirty-seven completed weeks of gestation.

\section{Low birth weight}

Birth weight of less than $2500 \mathrm{~g}$.

\section{Perinatal asphyxia}

A neonatal condition defied by five minute APGAR score of less than seven.

\section{Data extraction}

All of the research articles that were identified from searches of the electronic databases were imported into the ENDNOTE software version X5 (Tomson Reuters, USA) and duplicates were removed. Two authors (AGM and TMA) screened the titles and abstracts of identified articles by applying the inclusion criteria. Two authors (AGM and MAS) independently reviewed the full text. Final inclusion of the studies was determined by agreement of both reviewers and when there is disagreement, a third author (TMA) was involved. All the authors were involved in the discussion and agreed on the final inclusion. Before data extraction had begun, full-length articles of the selected studies were read to confirm for fulfilling the inclusion criteria. Then, data extraction was performed by two reviewers (AGM and TMA) independently. The selected studies were reviewed to extract data like; year of publication; author(s); study design; sample size; maternal outcomes; fetal outcomes; type of HDP; period of occurrence of the HDP; gestational age at the time of diagnosis; and antenatal care visit. When there was a disagreement in data extraction between the reviewers, it was resolved through discussion and mutual agreement between the investigators.

\section{Quality assessment}

All reviewers (AGM, MAS, TMA) independently assessed the quality of studies using strengthening the reporting of observational studies in epidemiology (STROBE) scale checklist quality assessment tool [17]. All of the included studies were assessed to have a quality of $>70 \%$ and, there were no studies excluded based on quality assessment.

\section{Statistical analysis and heterogeneity}

Statistical analyses were carried out by using Stata 14 (Stata Corp LP, College Station, TX) software to estimate the pooled prevalence of selected maternal and perinatal outcomes [18]. Statistical heterogeneity between studies was evaluated using the Cochran's Q test and $\mathrm{I}^{2}$ statistic [19]. $\mathrm{I}^{2}$ value of greater than 75 demonstrates that heterogeneity among the studies is high and probably a few studies are contributing to the final result. Random-effects model for estimating pooled effects was employed due to the high level of observed heterogeneity and was measured as proportions of outcomes with 95\% confidence intervals (CIs). Egger's regression asymmetry test with $p$-value $<0.05$ used as a cutoff to declare presence of statistically significant publication bias. The detail description of the original studies was presented in a table and forest plot.

\section{Results}

\section{Studies identified}

A total of 127 articles were identified from five electronic databases (MEDLINE, Scopus, PubMed, ScienceDirect, and Google Scholar). Out of these identified articles: 38 articles found duplicated and were removed; 49 articles excluded after reviewing their title; 16 articles excluded after reviewing their abstracts; and 11 articles excluded after a full text review (did not report the outcome variables). Finally, thirteen studies were included in the systematic review and meta-analysis (Fig. 1).

\section{Description of the studies}

Out of thirteen studies as demonstrated in table one; eleven studies were cross-sectional studies [20, 21, 23$26,28-32]$ while two studies followed a retrospective cohort study design [22, 27]. Four studies conducted in Southern Nations Nationalities and People (SNNPR) [22, 23, 27, 30]; four studies were conducted in Addis Ababa (capital city of Ethiopia) [24, 25, 31, 32]; three studies were from Oromia regional state [20, 26, 29]; one study in Amhara region [28]; and one study conducted in Somali regional state of Ethiopia [21]. The sample size of studies ranges from a minimum of 93 women [21] to a maximum of 1809 women [25]. All of the included studies defined hypertensive disorders of pregnancy as a Systolic blood pressure (SBP) of $140 \mathrm{mmHg}$ or higher and/ or diastolic blood pressure (DBP) of $90 \mathrm{mmHg}$ or higher on two or more consecutive occasions during pregnancy.

\section{Socio-demographic, ANC service utilization, and clinical characteristics of study participants}

Overall, thirteen studies with a total sample size of 5894 pregnant women were found to have one of the HDPs and included in the review [20-32]. A maximum of $52.5 \%$ in a study conducted in Jimma specialized hospital [20] to a minimum of $3.5 \%$ among women admitted at teaching hospitals in Addis Ababa [24] were not having any antenatal care visit. Furthermore, $52 \%$ of women from another study [26]; 22.2\% from a study in Amhara region [28]; and, $7.5 \%$ in Somalia regional state of Ethiopia [21] had no antenatal care visit. For other components of socio-demographic and clinical 


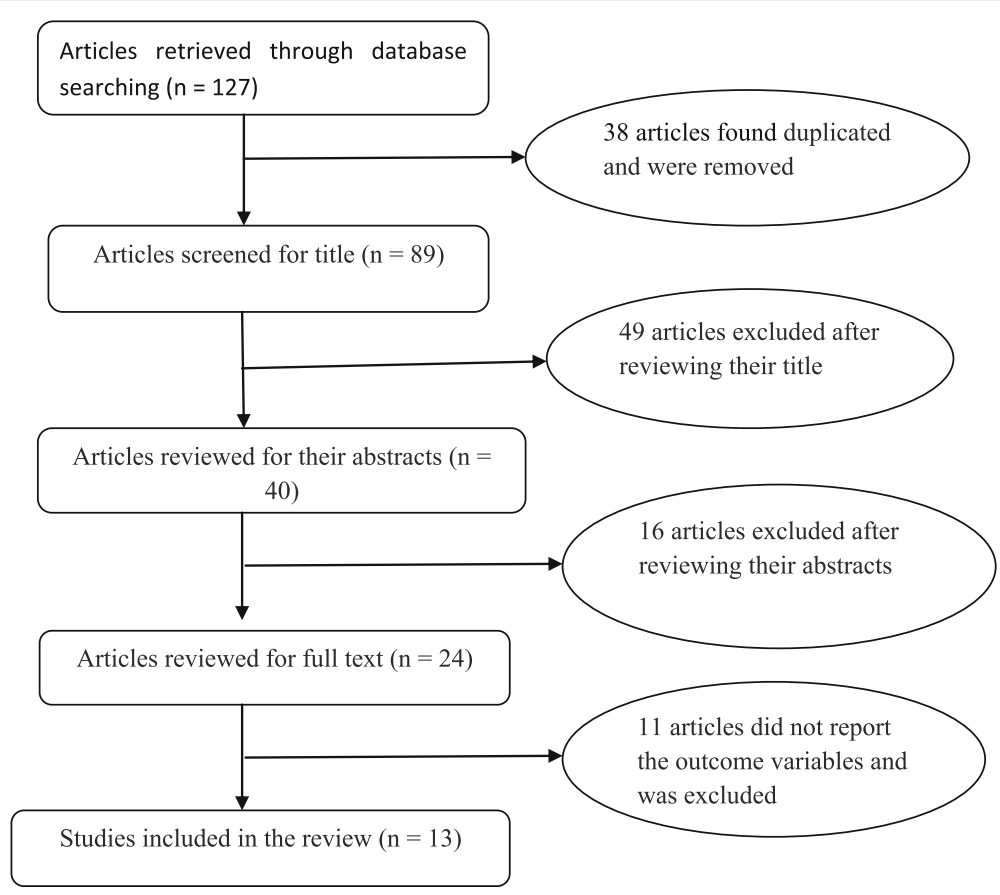

Fig. 1 Flow diagram of the studies included in the review

characteristics of women included in the review there were no adequate data to generate results.

\section{Hypertensive disorder of pregnancy (HDP)}

Among the five groups of HDP, preeclampsia - eclampsia syndrome was the most commonly reported type of HDP. For instance, preeclampsia accounts for $66.2 \%$ of mothers among women admitted with HDP in Jimma specialized hospital [20]; $72.9 \%$ among mother with HDP in a Southern Ethiopian study [23]; and, $82.7 \%$ in a study done in Addis Ababa [25]. Eclampsia was reported to account for $27.8 \%$ of women admitted for HDP in a study conducted at Amhara regional state [28]; 34.1\% in Southern study [27]; and, $24.2 \%$ in a study from Addis Ababa study. A study conducted in Somalia regional state of Ethiopia reported that $61 \%$ of the women with HDP were diagnosed during the antepartum period; $28 \%$ were diagnosed during the intrapartum period; and the remaining $10.7 \%$ were diagnosed in the postpartum period [21]. Most convulsions started during the antepartum period as compared to onsets during the intrapartum and postpartum periods. For instance, $38 \%$ of all convulsions in a study conducted at Oromia regional state started in the antepartum period; $18 \%$ occur during the intrapartum period; and the rest $44 \%$ convulsions started during the postpartum period [20]. Additionally, $86 \%$ of all the convulsions started during the antepartum period in a study conducted at teaching hospitals located at Addis Ababa [24] (Table 1).

\section{Maternal outcomes of HDP}

Among thirteen studies included in the review, nine studies reported rate of maternal death in women diagnosed to have HDP [20-25, 27, 28, 32]. As illustrated in the forest plot, the overall all rate of maternal death in Ethiopian women with HDP was estimated to be $4 \%$ [0.04 (0.02-0.06), $\left.\mathrm{I}^{2}=94.64 \%, P<0.01\right]$ (Fig. 2). The test of publication bias using the Egger's test was nonsignificant, $p$-value $>0.092$ (Fig. 6). Seven studies reported the prevalence of HELLP syndrome [20, 21, 24$26,29,31]$. As demonstrated in the forest plotthe prevalence of HELLP syndrome was estimated to be $13 \%$ [0.13 (0.10-0.16), $\left.\mathrm{I}^{2}=72.2 \%, p<0.01\right]$ (Fig. 3). Publication bias was checked by using the Egger's test that showed non-significant publication bias, p-value $>$ 0.428 (Fig. 6). Acute kidney injury was reported by six of the included studies [20,21, 23, 24, 26, 31]: the maximum rate of acute kidney injury was reported from a study conducted in Jimma specialized hospital $(24.2 \%)$ [20]; and, the minimum rate was reported from a study conducted in Addis Ababa (6.5\%) [24]. Placental abruption complicates as high as $15.3 \%$ of women with HDP in Addis Ababa [25]; and, as low as $1.3 \%$ in Southern Nations and Nationalities of Ethiopia [30]. The highest rate of pulmonary edema was reported from one study conducted in Jimma specialized hospital (20.1\%) [20]; followed by a study from Addis Ababa (17.5\%) [25]. Aspiration pneumonia complicates $17.5 \%$ of women with the diagnosis of HDP in one study [25]. 


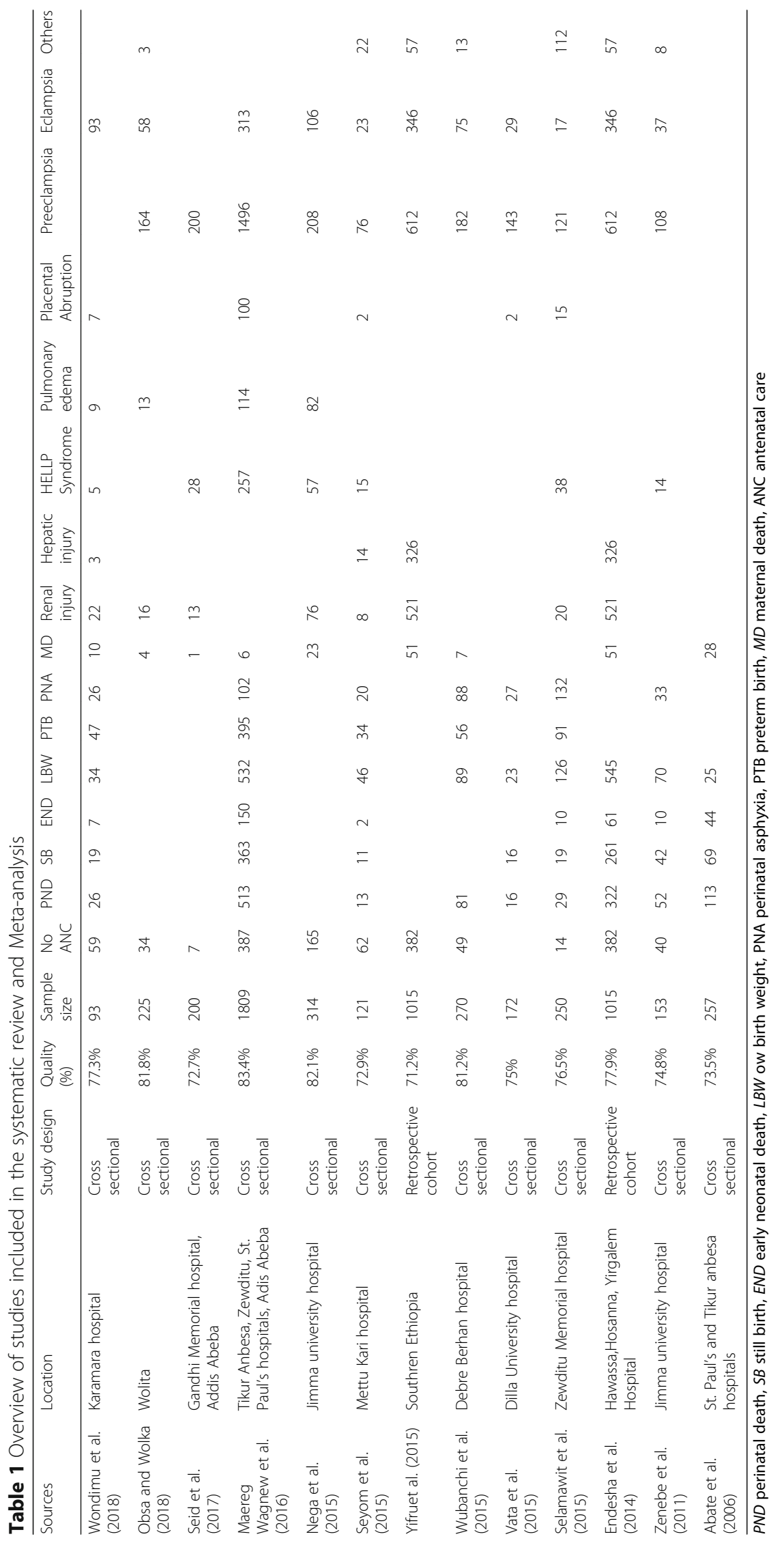




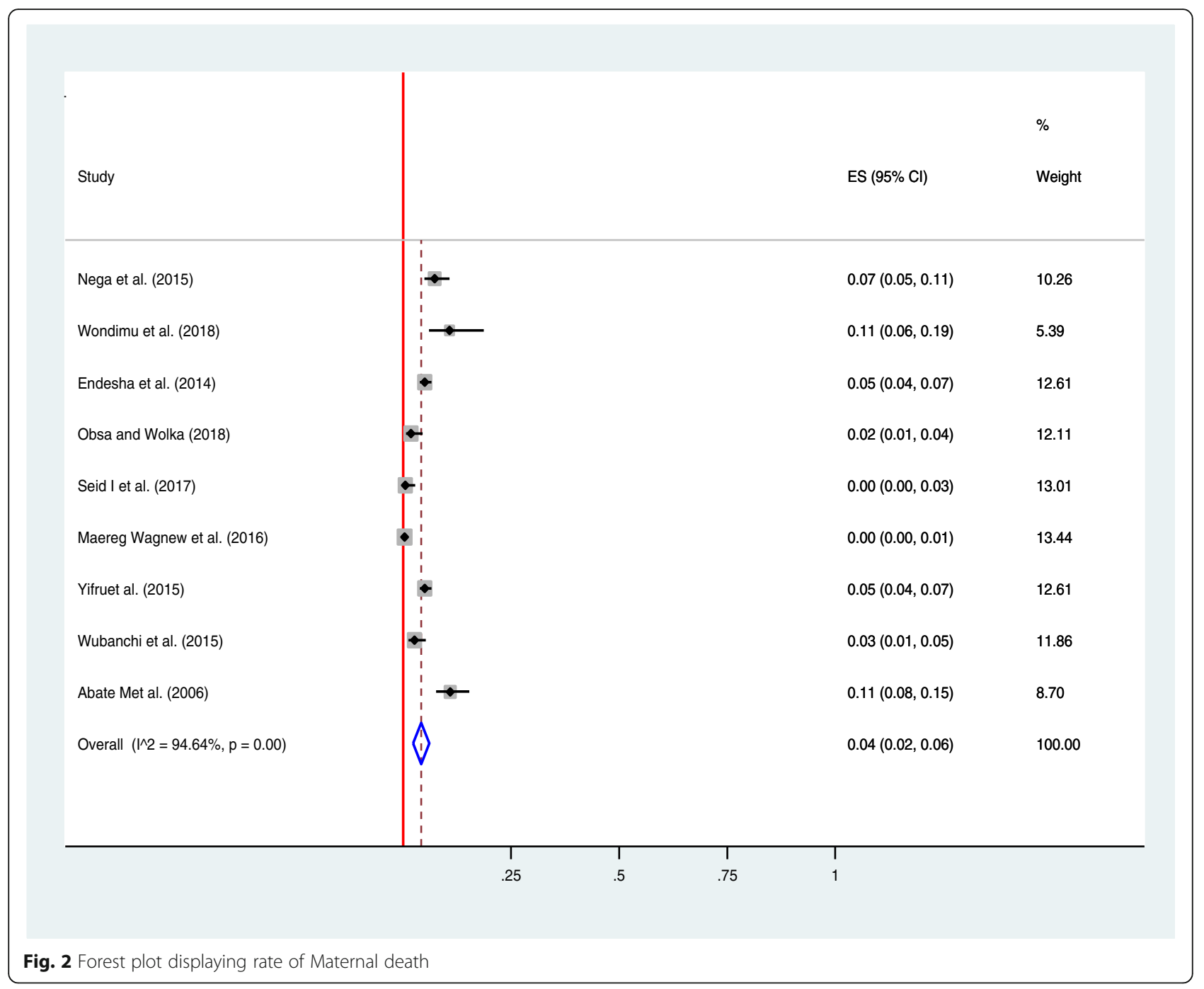

\section{Perinatal outcomes of HDP}

Among thirteen studies included in the review, nine studies reported rate of perinatal death in mothers diagnosed with HDP [21, 22, 25, 26, 28-32]. As illustrated in the forest plot, perinatal death was observed in onefourth of women [0.25 (0.18-0.32), $\mathrm{I}^{2}=95.94 \%, p<0.01$ ] (Fig. 4). Egger's test was conducted and illustrated that the publication bias is not statistically significant, $p$ value $>0.576$ (Fig. 6). The rate of stillbirths were most common than the rate of early neonatal deaths. For instance, in one study the rate of stillbirth was almost four folds higher than early neonatal deaths ( $81 \%$ vs. $19 \%)$ [22]. The frequency of giving birth to a low birth weight neonate was assessed using eight studies $[21,22,25,26$, $28-31]$. The overall rate of having a low birth weight newborn was found to be 37\% [0.37 (0.27-0.48\%), $\mathrm{I}^{2}=$ $97.40 \%, p<0.01$ ] (Fig. 5). Egger's test was employed to see for publication bias and found non-significant, $p$ value $>0.859$ (Fig. 6). Perinatal asphyxia was reported by six studies [21, 26, 28-31]: the highest rate being $52.8 \%$ in Addis Ababa [31] and the lowest rate being 13.4\% in Southern Ethiopia [30]. Preterm birth complicates as high as $65.3 \%$ of women with HDP in Somalia regional state of Ethiopia [21] to as low as $31 \%$ in a study conducted at Oromia regional state [26].

\section{Discussion}

In the current review, $4 \%$ of women in Ethiopia diagnosed with hypertensive disorders of pregnancy ended up in maternal death. This finding is similar with a study conducted in Pakistan that reported maternal death rate of $6.23 \%$ among women with hypertension [33]. While the case fatality rate for eclampsia ranged from 0 to $1.8 \%$ in high-income countries. Such a wide disparity is due to both differences in incidence and quality of obstetric care for hypertensive disease in pregnancy [41]. The rate of maternal death from this review is much higher than a study conducted in Saudi Arabia which reported a 


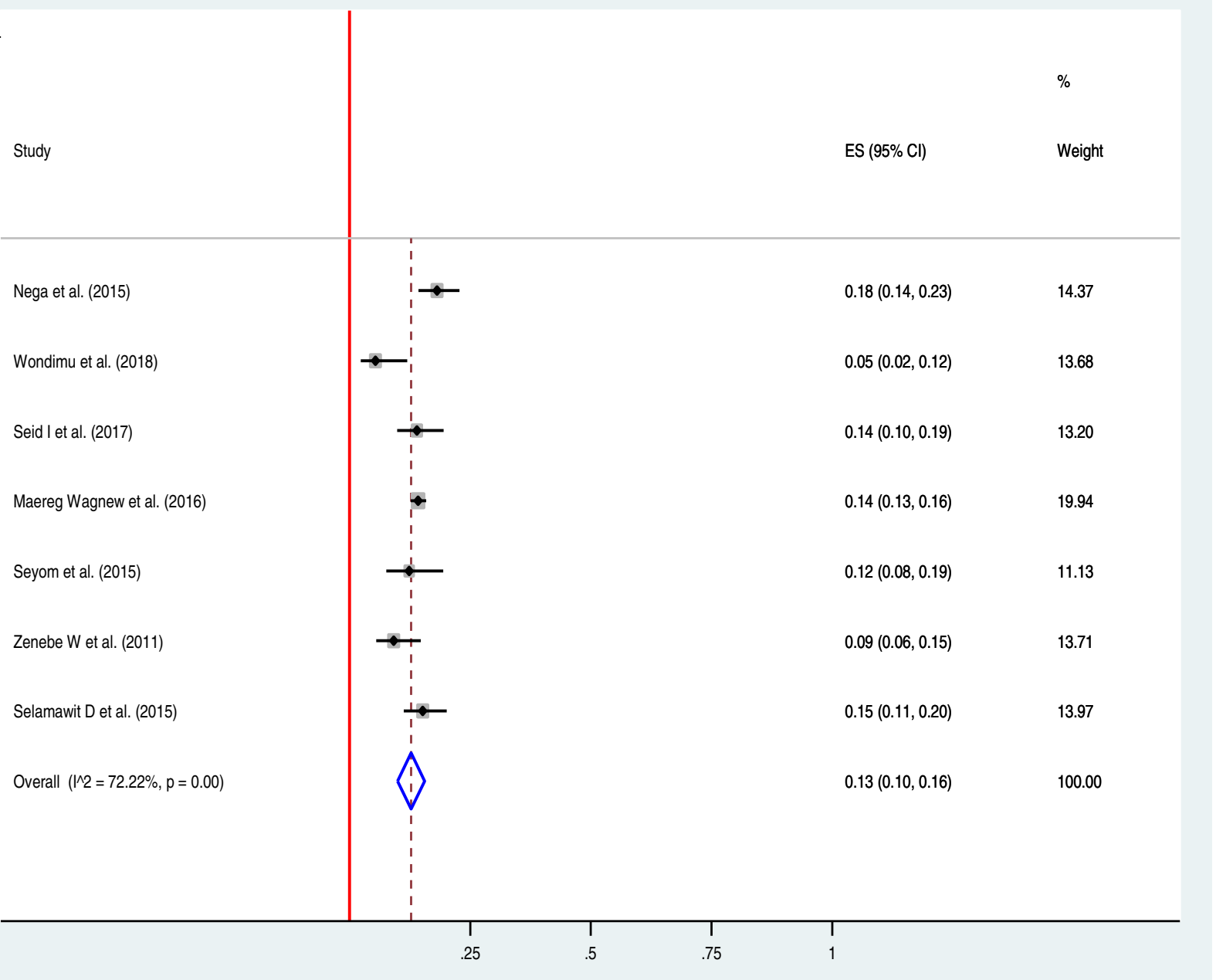

Fig. 3 Forest plot displaying rate of HELLP syndrome

maternal death of $1.3 \%$. The Saudi Arabian study was conducted in a tertiary center that may explain the lower reported rate of maternal death as compared to the current finding [34]. This could also be justified by the high number of participants with no antenatal care (ANC) follow up in some of the studies included in the current review. Furthermore, differences in the quality of maternal and neonatal health care service may have been caused this disparity.

In Ethiopia, HELLP syndrome complicates $13 \%$ of women with hypertensive disorders of pregnancy. This finding is line with a study conducted by Karumanchi et al. which reported a 10 to $20 \%$ rate of HELLP syndrome among women admitted for the diagnosis of preeclampsia [35]. The much higher rate of HELLP syndrome as compared to women without hypertensive disorders $(0.5-0.9 \%)$ could be explained by the pathological course of the disease. In preeclampsia for example, defective placental vascular remodeling around mid second trimester of pregnancy with the second round of trophoblastic invasion into the deciduas results in inadequate placental perfusion. The hypoxic placenta then releases various placental factors such as soluble vascular endothelial growth factor receptor-1 (sVEGFR1 ), which then binds vascular endothelial growth factor (VEGF) and placental growth factor (PGF), causing endothelial cell and placental dysfunction by preventing them from binding endothelial cell receptors. This results in increased platelet activation and aggregation leading to low platelet count, haemolysis and hepatic injury $[36,37]$.

Pulmonary edema, acute kidney injury, hepatic injury, placental abruption, aspiration pneumonia, and other life treating complications were also reported by included studies. The above mentioned complications were reported by the 2014 world health organization (WHO) 


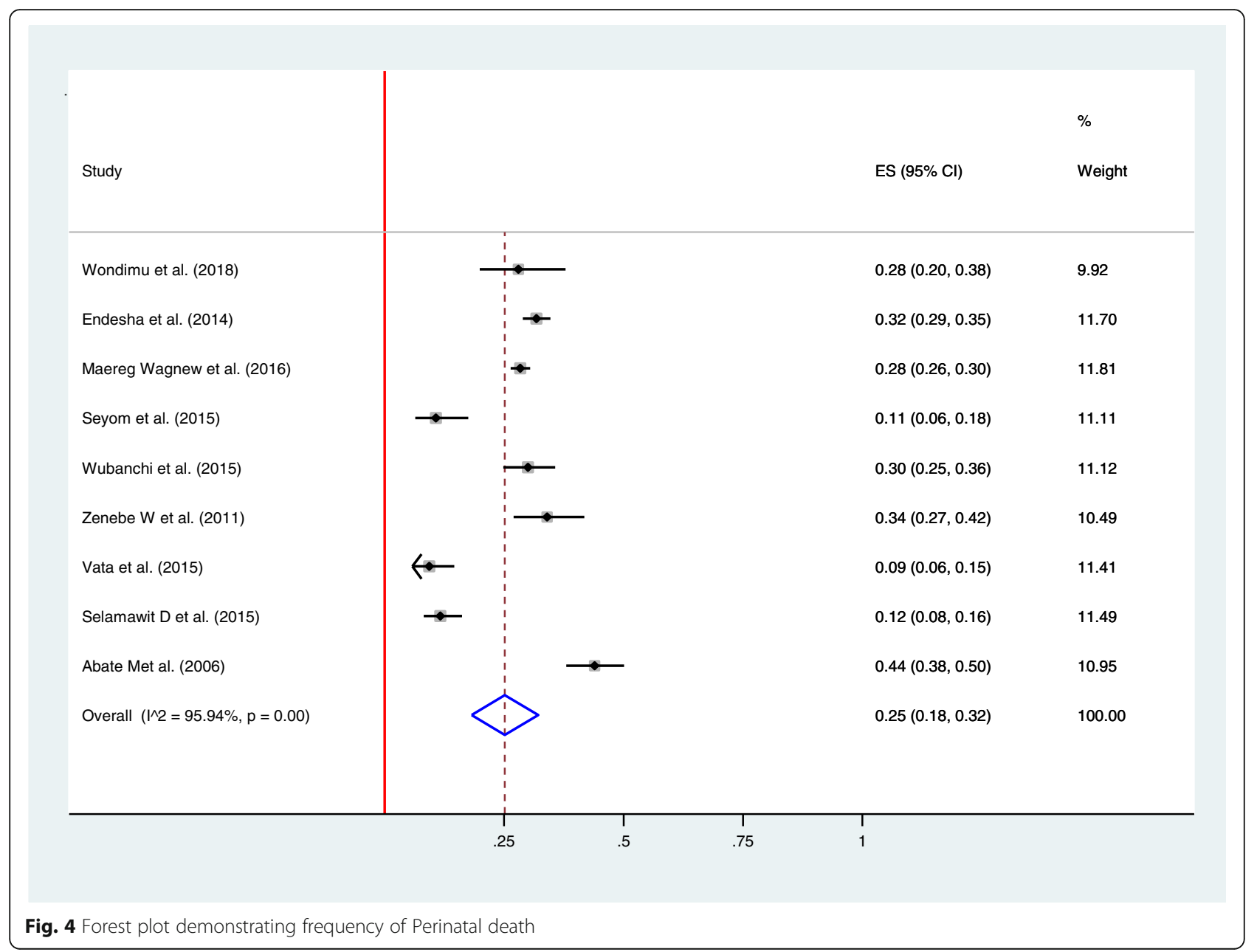

multinational analysis using 29 countries from Africa, Asia, Latin America and Middle East [3, 4].

In this review, the prevalence of perinatal mortality among women with hypertensive disorders of pregnancy in Ethiopia was found to be $25 \%$. This finding is in line with another study conducted in Pakistan which reported a perinatal mortality of $17.5 \%$ [33]. However, this is in contrary to a Norway study conducted among pregnant women that reported a perinatal mortality of only $9.2 \%$. This disparity may be explained by differences in the quality of follow up a pregnant woman receives [38].

In this review, low birth weight complicates more than one-third of women with HDP in Ethiopia (37\%). This rate is much higher than the rates reported in a study conducted in China (6.8\%); and, a review conducted among women with chronic hypertension (16.9\%). As per the 2016 Ethiopian Demographic and Health Statistics (EDHS) report, the rate of low birth weight in the general population is $13 \%$ that could explain the existing higher number of low birth weight in Ethiopia [9].

Perinatal asphyxia, preterm birth and other complications have been also reported in the studies included in the review. The above mentioned complications have been reported by other original articles and systematic reviews $[39,40]$. Although the exact mechanisms for the above mentioned perinatal complications are not yet well known, the most acceptable theory for the development of preeclampsia is defective remodeling of spiral arteries. Defective placentation affects utero-placental blood flow and leads to complications such as preterm birth, low birth weight, perinatal asphyxia, and fetal growth restriction [14, 15]. An Indian study reported that the most common neonatal complication was prematurity (23.65\%), low birth weight (7.52\%) and intrauterine growth restriction (9.67\%) [16].

\section{Strength and limitations of the study}

This review is the first to review the maternal and fetal outcomes among women with all types of HDPs in Ethiopia. The limited numbers of studies evaluating outcomes made it impossible to generate strong conclusions. The included studies were also conducted primarily in tertiary health centers, and the data may not be representative of outcomes in low-level facilities or in 


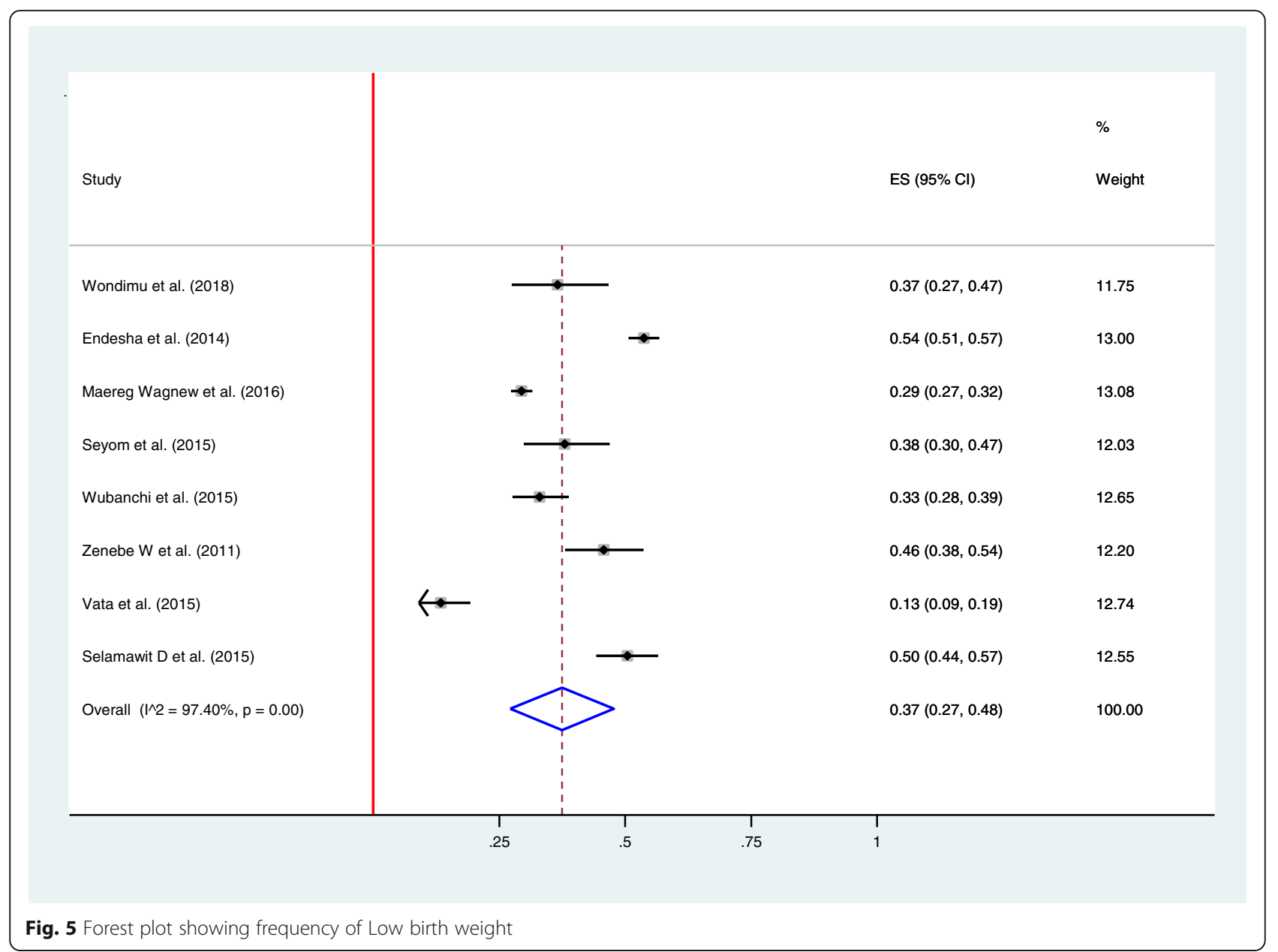

the community. Furthermore, there is a high level of heterogeneity among the included studies that should be taken in consideration while using the results of the review. Despite these possible limitations, the review provides useful information that may contribute to both the filling of the gaps in the national maternal morbidity research agenda and guiding practice and policy about the most frequent complications of HDP.

\section{Conclusions and recommendations}

This review demonstrated the high prevalence of perinatal and maternal mortality among pregnant women with one of the HDP in Ethiopia. Moreover, other severe maternal and perinatal complications such as HELLP syndrome, placental abruption, pulmonary edema, hemolytic anemia, renal damage, prematurity, perinatal asphyxia, as well as low birth weight were also commonly reported.

Based on the above mentioned results, it is recommended to intervene at three levels so as to improve the maternal and fetal outcomes of hypertensive disorders in Ethiopia and to ensure the safety of a pregnant woman and her baby. Giving the above mentioned fact of poor antenatal care (ANC) service utilization, community based health education can be one possible level of intervention to improve the health outcomes of women with HDP by improving maternal health service utilization. The second possible level of intervention could be early detection and early referral of pregnant women with hypertensive disorder. Policies and strategies that may enhance the health professionals' capacity should be advocated. The other possible level of intervention could be, optimizing the quality of care that a pregnant woman with hypertensive disorders receives. Additionally, it is recommended to have easily available and affordable laboratory testing; frequent maternal and fetal monitoring; increase accessibility of antihypertensive and anticonvulsive drugs; increase preparation for neonatal resuscitation; and, improving quality of neonatal intensive care units. It is also recommended to develop a uniform systematic registration system of maternal and perinatal outcomes of HDP in the country. 
Marsha et al. BMC Pregnancy and Childbirth

(2019) 19:458

Page 10 of 12

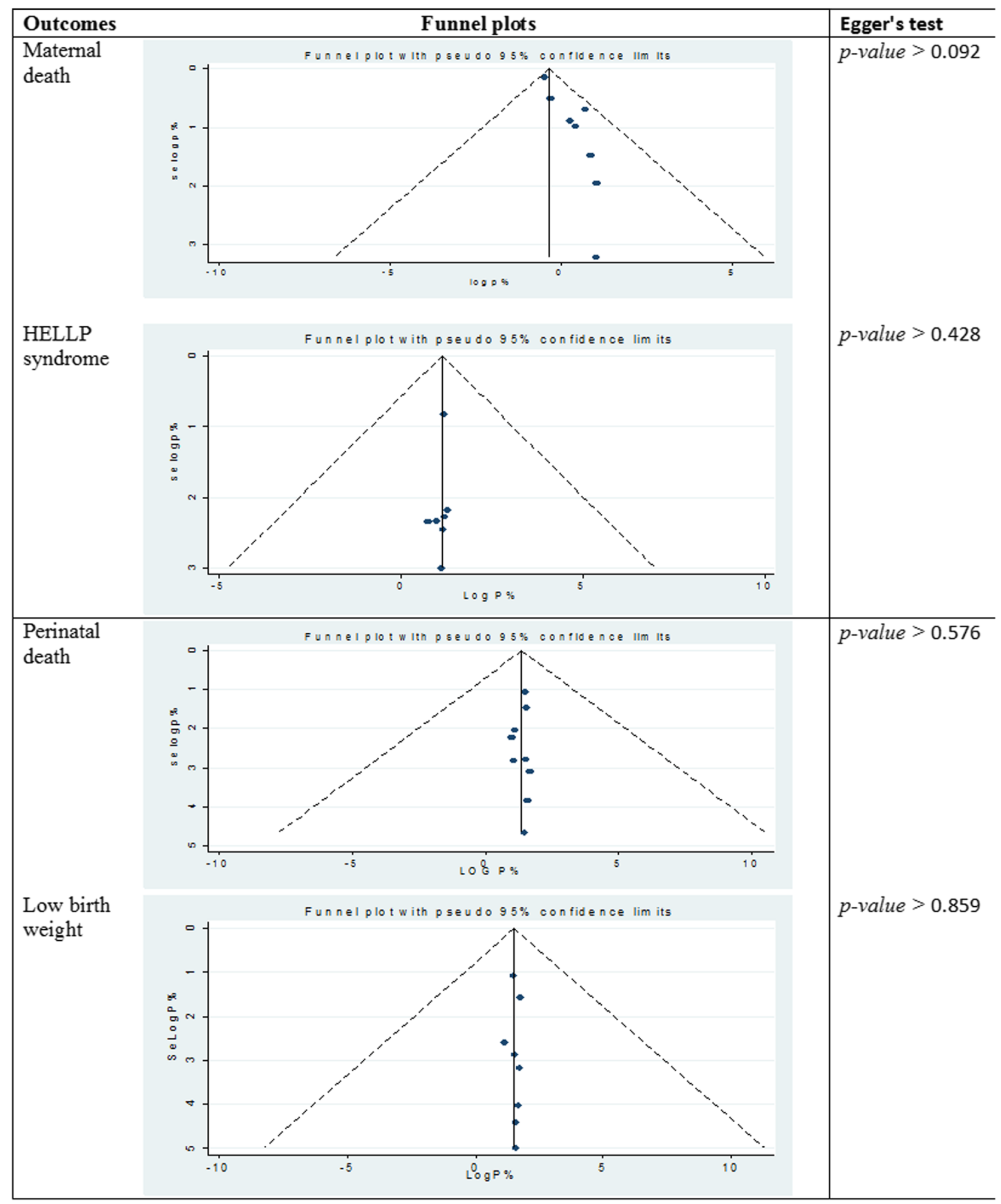

Fig. 6 Publication bias of maternal and fetal outcomes 


\section{Abbreviations}

ANC: Antenatal care; Cl: Confidence interval; HDP: Hypertensive disorders of pregnancy; WHO: World Health Organization

\section{Acknowledgements}

We acknowledge the authors of the included articles.

\section{Authors' contribution}

AGM conceived the study and wrote the final manuscript. AGM, TMA, MAS involved in the acquisition of data, performed review, analyzed the data, and wrote the initial draft of the manuscript. All authors read and approved the final version of the manuscript.

\section{Funding}

No funding source.

\section{Availability of data and materials}

All relevant materials and data supporting the findings of this review are included within the manuscript.

\section{Ethics approval}

Our study is an investigation of the literature and does not need ethica approval for retrieving the already available public content.

\section{Consent for publication}

Not applicable.

\section{Competing interests}

The authors declare that they have no competing interests.

\section{Author details}

'Department of Gynecology and Obstetrics, School of Medicine, College of Medicine and Health Sciences, University of Gondar, P.O. Box: 196, Gondar, Ethiopia. ${ }^{2}$ Department of Clinical Pharmacy, School of Pharmacy, College of Medicine and Health Sciences, University of Gondar, P.O. Box: 196, Gondar, Ethiopia.

Received: 26 November 2018 Accepted: 21 November 2019

\section{Published online: 03 December 2019}

\section{References}

1. Oberts JM, Pearson G, Cutler J, et al. Summary of the NHLBI working group on research on hypertension during pregnancy. Hypertension. 2003:41:43745.

2. Berhe AK, Kassa GM, Fekadu GA, Muche AA. Prevalence of hypertensive disorders of pregnancy in Ethiopia: a systemic review and meta-analysis. BMC Pregnancy Childbirth. 2018;18(1):34.

3. Khan KS, Wojdyla D, Say L, Gulmezoglu AM, Van Look PF. WHO analysis of causes of maternal death: a systematic review. Lancet. 2006;367:1066-74.

4. Firoz T, Sanghvi $H$, Merialdi M, von Dadelszen P. Pre-eclampsia in low and middle income countries. Best Pract Res Clin Obstet Gynaecol. 2011;25:53748

5. Adu-Bonsaffoh K, Obed SA, Seffah JD. Maternal outcomes of hypertensive disorders in pregnancy at Korle Bu Teaching Hospital, Ghana. Int J Gynaecol Obstet. 2014:127(3):238-42.

6. Berhan $Y$, Berhan A. Causes of maternal mortality in Ethiopia: a significant decline in abortion related death. Ethiop J Health Sci. 2014;24:15-28.

7. Ukah UV, De Silva DA, Payne B, Magee LA, Hutcheon JA, Brown H, et al. Prediction of adverse maternal outcomes from pre-eclampsia and othe hypertensive disorders of pregnancy: a systematic review. Pregnancy Hypertens. 2018;11:115-23.

8. Steegers EA, von Dadelszen P, Duvekot JJ, Pijnenborg R. Pre-eclampsia. Lancet. 2010;376:631-44

9. Central Statistical Agency (CSA) [Ethiopia] and ICF. Ethiopia Demographic and Health Survey 2016. Addis Ababa and Rockville: CSA and ICF; 2016.

10. Abalos E, Cuesta C, Carroli G, Qureshi Z, Widmer M, Vogel JP, Souza JP, on behalf of the WHO Multicountry Survey on Maternal and Newborn Health Research Network. Pre-eclampsia, eclampsia and adverse maternal and perinatal outcomes: a secondary analysis of the World Health Organization Multicountry Survey on Maternal and Newborn Health. BJOG. 2014; 121(Suppl. 1):14-24.
11. Roberts JM, Pearson G, Cutler J, Lindheimer M. Summary of the NHLBI Working Group on research on hypertension during pregnancy. Hypertension. 2003;41(3 I):437-45.

12. Nusrat N, Ahson M, Munir A. Hypertensive disorders of pregnancy; frequency, maternal and perinatal out comes. J Pakistan Army Med Corps. 2010;26(1):119-23.

13. Yücesoy $G$, Ozkan S, Bodur $H$, et al. Maternal and perinatal outcome in pregnancies complicated with hypertensive disorder of pregnancy: a seven year experience of a tertiary care center. Arch Gynecol Obstet. 2005;273(1): 43-9.

14. Palatnik A, Grobman WA, Miller ES. Is a history of preeclampsia associated with an increased risk of a small for gestational age infant in a future pregnancy? Am J ObstetGynecol. 2016;215(3):355.e1.

15. Bramham K, Briley AL, Seed $P$, et al. Adverse maternal and perinatal outcomes in women with previous preeclampsia: a prospective study. Am J ObstetGynecol. 2011;204(6):512.e1.

16. Aabidha PM, Cherian AG, Paul E, Helan J. Maternal and fetal outcome in pre-eclampsia in a secondary care hospital in South India. J Family Med Prim Care. 2015:4(2):257-60.

17. vonElm E, Altman DG, Egger M, Pocock SJ, Gøtzsche PC, Vandenbroucke JP. The strengthening the reporting of observational studies in epidemiology (STROBE) statement: guidelines for reporting observational studies. J Clin Epidemiol. 2008;61(4):344-9.

18. StataCorp L. Stata Statistical Software: Release 14. [computer program]. StataCorp LP. 2015.

19. Huedo-Medina TB, Sánchez-Meca J, Marín-Martínez F, Botella J. Assessing heterogeneity in meta-analysis: Q statistic or $\mathrm{I}^{2}$ index? Psychol Methods. 2006;11(2):193.

20. Desalegn N, Haile M. Causes of Admission and out Comes Among Preeclampsia and Eclampsia Mothers Admitted to Jimma University Specialized Hospital Intensive Care Unit. Clin Med Res. 2015;4(5):154-9. https://doi.org/10.11648/j.cmr.20150405.16.

21. Gudu W, Bekele D. A prospective review of eclampsia at a regional hospital, Eastern Ethiopia: incidence, clinical correlates, management and pregnancy outcome. Ethiop Med J. 2018;56:125-132.

22. Endeshaw G, Berhan Y. Perinatal outcome in women with hypertensive disorders of pregnancy: a retrospective cohort study. Int Schol Res Not. 2015:2015:208043.

23. Obsa MS, Wolka E. Maternal outcome of pregnant mothers with hypertensive disorder of pregnancy at hospitals in Wolaita Zone, Southern Ethiopia. J Preg Child Health. 2018;5:375. https://doi.org/10.4172/2376-127X.1000375.

24. Seid I, et al. Maternal outcomes of preeclampsia in an Ethiopian Gynecologic Hospital. Ann Med Health Sci Res. 2017;7:16-21.

25. Wagnew M, Dessalegn M, Worku A, Nyagero J. Trends of preeclampsia/ eclampsia and maternal and neonatal outcomes among women delivering in Addis Ababa selected government hospitals, Ethiopia: a retrospective cross sectional study. Pan Afr Med J. 2016:25(Suppl 2):12.

26. Seyom E, Abera M, Tesfaye M, Fentahun N. Maternal and fetal outcome of pregnancy related hypertension in Mettu Karl Referral Hospital, Ethiopia. J Ovarian Res. 2015;8:10

27. Berhan $Y$, Endeshaw G. Maternal mortality predictors in women with hypertensive disorders of pregnancy: a retrospective cohort study. Ethiop J Health Sci. 2015:25(1):89-98.

28. Terefe W, Getachew Y, Hiruye A, Derbew M, Mariam DH, Mammo D, et al. Patterns of hypertensive disorders of pregnancy and associated factors at DebreBerhan referral hospital, north Shoa, Amhara region. Ethiop Med J. 2015;(Suppl 2):57-65.

29. Wolde Z, Segni H, Woldie M. Hypertensive disorders of pregnancy in Jimma university specialized hospital. Ethiop J Health Sci. 2011;21(3):147-54.

30. Vata PK, Chauhan NM, Nallathambi A, Hussein F. Assessment of prevalence of preeclampsia from Dilla region of Ethiopia. BMC Res Notes. 2015;8:816.

31. Selamawit D, Sisay T. Maternal and perinatal outcomes of pregenanciescomplecated by preeclampsia/eclampsia at zewditu memorial hospital. Addis Ababa Aniversity School of Graduate Studies Faculty of Medicine 2015.

32. Abate $M$, Lakew Z. Eclampsia a 5 years retrospective review of 216 cases managed in two teaching hospitals in Addis Ababa. Ethiop Med J. 2006; 44(1):27-31.

33. Hossain N, Shah N, Khan N, Lata S, Khan NH. Maternal and perinatal outcome of hypertensive disorders of pregnancy at a tertiary care hospital. J Dow Univ Health Sci Karachi. 2011;5(1):12-6. 
34. Subki AH, Algethami MR, Baabdullah WM, Alnefaie MN, Alzanbagi MA, Alsolami RM, et al. Prevalence, risk factors, and fetal and maternal outcomes of hypertensive disorders of pregnancy: a retrospective study in Western Saudi Arabia. Oman Med J. 2018;33(5):409-15.

35. Karumanchi SA, Maynard SE, Stillman IE, Epstein FH, Sukhatme VP. Preeclampsia: a renal perspective. Kidney Int. 2005;67(6):2101-13.

36. Steinborn A, Rebmann V, Scharf A, Sohn C, Grosse-Wilde H. Soluble HLA-DR levels in the maternal circulation of normal and pathologic pregnancy. Am J Obstet Gynecol. 2003;188:473-9.

37. Agatisa PK, Ness RB, Roberts JM, Costantino JP, Kuller LH, McLaughlin MK. Impairment of endothelial function in women with a history of preeclampsia: an indicator of cardiovascular risk. Am J Physiol Heart Circ Physiol. 2004;286:H1389-93.

38. Ahmad A, Samuelsen S. Hypertensive disorders in pregnancy and fetal $371^{\circ}$ $121^{\circ}$ death at different gestational lengths: a population study of 2 pregnancies. BJOG. 2012;119:1521-8.

39. Browne JL, Vissers KM, Antwi E, Srofenyoh EK, Van der Linden EL, Agyepong $I A$, et al. Perinatal outcomes after hypertensive disorders in pregnancy in a low resource setting. Trop Med Int Health. 2015;20(12):1778-86.

40. Ye C, Ruan Y, Zou L, Li G, Li C, et al. The 2011 survey on hypertensive disorders of pregnancy (HDP) in China: prevalence, risk factors, complications, pregnancy and perinatal outcomes. PLoS One. 2014;9(6): e100180. https://doi.org/10.1371/journal.pone.0100180.

41. Ronsmans C, Campbell O. Quantifying the fall in mortality associated with interventions related to hypertensive diseases of pregnancy. BMC Public Health. 2011;11(3):S8

\section{Publisher's Note}

Springer Nature remains neutral with regard to jurisdictional claims in published maps and institutional affiliations.

Ready to submit your research? Choose BMC and benefit from:

- fast, convenient online submission

- thorough peer review by experienced researchers in your field

- rapid publication on acceptance

- support for research data, including large and complex data types

- gold Open Access which fosters wider collaboration and increased citations

- maximum visibility for your research: over $100 \mathrm{M}$ website views per year

At BMC, research is always in progress.

Learn more biomedcentral.com/submissions 